\title{
Breastfeeding and feeding practices in the first year of life and its association with overweight and obesity of children in Mexico
}

\section{Armando Arredondo 1}

(iD https://orcid.org/0000-0002-2768-9966

Oscar Benjamin Reséndiz Lugo 2

iD https://orcid.org/0000-0001-6103-9126

Emanuel Orozco 3

iD https://orcid.org/0000-0002-6550-7385

Christian Paul Torres de la Rosa 4

iD https://orcid.org/0000-0002-3287-5413

1,3,4 Centro de Investigación en Sistemas de Salud. Instituto Nacional de Salud Pública. Avenida Universidad 655. Colonia Santa María Ahuacatitlán. 62100 Cuernavaca, Morelos, México. Email: ciss09@insp.mx

2 Facultad de Ciencias Naturales. Universidad Autónoma de Querétaro. Querétaro, México.

\begin{abstract}
Objectives: to evaluate feeding practices in the first year of life and their association with the development of overweight and obesity in children in Mexico.

Methods: the association between overweight and obesity with different feeding practices were evaluated. The data was processed using the statistical package Stata version 14 using logistic regression models.

Results: 396 children were evaluated; the prevalence of overweight and obesity was $6 \%$ and $7.7 \%$ presented a possible risk of overweight. $6.9 \%$ had exclusive breastfeeding in the first 6 months of life and $71.7 \%$ were fed infant formula. The variables significantly associated with the development of overweight and obesity in the first year of life were the age of the child ( $p=0.043, R R=0.57$ ), the introduction of fluids in the first three days of life ( $p=0.02$, $R R=2.90)$, consumption of foods with a high sugar content ( $p=0.01, R R=0.25)$, consumption of milk other than breast ( $p=0.02, R R 3.25)$ and egg consumption $(p=0.05 ; R R=0.28)$.

Conclusions: our results show that it is essential to attend complementary feeding practices and reinforce exclusive breastfeeding in the first year of life, as measures to prevent overweight and obesity to improve health in childhood.

Key words Breastfeeding, Overweight, Obesity, Infant nutrition
\end{abstract}

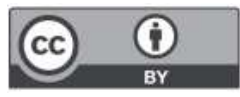




\section{Introduction}

The period that includes the prenatal, neonatal, and post-neonatal stages is related to the morphological and physiological development of every human being in the life cycle. ${ }^{1}$ Linear growth and nutritional status in the first year will depend on practices and care provided to the infant. $2-5$

Currently, the development of overweight and obesity in early ages is the focus of attention and continues to be part of the Sustainable Development Goals (SDG) despite the stabilization of the phenomenon in recent years. ${ }^{6}$ The World Health Organization (WHO) in 2016, showed that 41 million children under 5 years of age were overweight or obese, this was defined as an abnormal or excessive accumulation of fat which could be harmful to health. ${ }^{7}$ According to the National Survey of Health and Nutrition (ENSANUT 2018), the combined prevalence of overweight (OW) and obesity (OB) in children under 5 years old was $8.3 \%, 8$ lower than that presented in 2012 , which was $9.7 \% .9$

Overweight and obesity in early childhood make it clear that genetic, biological, and social factors combined with the absence of exclusive breastfeeding (EBF), the introduction of food before 6 months of age, the excessive consumption of breast milk substitutes, and inclusion in unhealthy dietary patterns represent a latent risk for the development of multiple comorbidities in childhood. Definitely, during the first two years of life, OW and OB have a greater possibility of suffering from metabolic diseases, diabetes, hypertension, and heart disease in adulthood and of course important consequences in physical and mental health. ${ }^{10-13}$

The development of this work contributes to the evidence on the importance of EBF in children under two years of age, as well as emphasizes the social gaps that exist around the subject, in the same, way it is emphasized that at this age there is high consumption of energy-dense foods and low nutritional quality.

The purpose of this manuscript is to evaluate breastfeeding and feeding practices in the first year of life and their association with the development of overweight and obesity in Mexican children.

\section{Methods}

Study based on a cross-sectional, analytical, descriptive, and explanatory design with prospective temporality. The sample size corresponds to 396 children under 1 year of age, descendants of women belonging to a cohort in Mexico "NUTTSEA".14-15 Inclusion criteria were considered a) to be a motherchild binomial of the NUTTSEA cohort and $b$ ) to have complete anthropometric data. Data collection was carried out through the questionnaire "Parenting practices in the first 3 years of life" addressed to participating mothers, validated in the Mexican population, used in national health surveys. 9 The application of the questionnaire was carried out at the homes of the minors in three municipalities of the state of Morelos, Mexico in the period from February to July 2018 corresponding to stage II of the "NUTTSEA" cohort in Mexico. The data correspond to the first lift of the minors who will be incorporated into the NUTTSEA cohort.

The nutritional status of the minors was evaluated about the weight and length they presented at the time of the intervention. An infantometer and a tray scale were used for anthropometry. Nutrition graduates (in pairs), previously trained and standardized, were responsible for carrying out the measurements, one served as an anthropometrist and the other noted the result. The minors were weighed in their underwear and the company of their parents and the length was taken without shoes and in an upright position. Two anthropometric tests were carried out to avoid measurement errors.

Taking as reference the growth standards of the WHO, 16 weight for age (W/A), length for age (L/A) were evaluated, and weight for length (W/L). A normal nutritional status was considered between -1 standard deviation (SD) and $+1 \mathrm{SD}$, a status of the possible risk of overweight (PROW) was considered within $+1 \mathrm{SD}$ and $+2 \mathrm{SD}$, for overweight (OW) the location between $+2 \mathrm{SD}$ and $+3 \mathrm{SD}$ and finally for the diagnosis of obesity (OB), all those minors located above $+3 \mathrm{SD}$ were considered.

Within the Breastfeeding Practices (BFP) included; Exclusive breastfeeding (EBF), predominant breastfeeding (PBF), and early initiation of breastfeeding (EIBF). For each of the above, it was considered; EBF: Feeding exclusively with breast milk in the first 6 months; BFP: Feeding with breast milk and non-nutritive fluids in the first 6 months and EIBF: Minors breastfed within the first hour after birth.

Eating practices were studied based on the age of introduction and frequent consumption of liquids and food based on a questionnaire adapted from ENSANUT 2012. The food groups were organized according to the WHO16 (Table 1): plain water, whey, non-breast milk, non-nutritive liquids, nutritious liquids, cereals and legumes, fruits and vegetables, red meat, white meat, cold cuts, egg, dairy and 
miscellaneous. In addition, the consumption of foods high in iron (Those with greater bioavailability of iron, fortified foods, and supplements) and foods with high sugar content (Those that threaten to exceed $5 \%$ of the total recommended daily caloric value in children under 1 year of age). Questionnaire "Parenting practices in the first 3 years of life, inquired information on the current state, that is, the day before the interview, also referred to as statusquo. These indicators refer only to the fact of whether or not the food was consumed, but not to the quantity consumed, so they cannot be used to calculate the adequacy of quantities consumed.

Data analysis was performed using the Stata version 14 statistical package. Descriptive data represented in proportions and measures of central tendency; two multivariate logistic regression models adjusted for age and sex were developed to determine the association of PROW, OW, and OB (dependent variable) with breastfeeding and feeding practices, respectively. For this purpose, the odds ratio or the possibility of the risk of having PROW, $\mathrm{OW}$, and $\mathrm{OB}$ were described, values equal to or less than $0.05,0.01$, and 0.001 were taken as statistical significance, with a CI95\%.

\section{Results}

The results correspond to a total of 396 boys and girls who made up the final sample studied. Of the

Table 1

Complementary feeding practices in minors of the cohort NUTTSEA 2018

\begin{tabular}{|c|c|c|c|c|c|c|c|c|}
\hline & $\begin{array}{l}(\mathrm{N}=150) \\
37.87 \%\end{array}$ & \multicolumn{3}{|c|}{$\begin{array}{l}\text { Food introduction age } \\
\text { in months, under } \\
6 \text { months }\end{array}$} & \multirow{2}{*}{$\begin{array}{c}(\mathrm{N}=246) \\
62.12 \% \\
\%\end{array}$} & \multicolumn{3}{|c|}{$\begin{array}{l}\text { Food introduction age in months, } \\
\text { over } 6 \text { months }\end{array}$} \\
\hline & $\%$ & Mean & SD & $\mathrm{Cl} 95 \%$ & & Mean & SD & $\mathrm{Cl} 195 \%$ \\
\hline Simple water & 81.8 & 4.0 & 1.4 & $72.1-88.6$ & 97.9 & 4.6 & 1.5 & $93.7-99.3$ \\
\hline Serum or medicated drops & 17.0 & 3.2 & 1.6 & $10.4-26.5$ & 21.3 & 5.0 & 2.9 & $15.3-28.8$ \\
\hline Milk other than breast $¥$ & 39.7 & 2.7 & 1.6 & $29.9-50.5$ & 44.1 & 3.7 & 2.6 & $36.1-52.4$ \\
\hline Non-nutritive liquids $\ddagger$ & 46.5 & 4.2 & 1.5 & $36.2-57.2$ & 82.7 & 5.4 & 1.4 & $75.6-88.1$ \\
\hline Nutritive liquidst & 6.8 & 5.1 & 1.8 & $3.0-14.5$ & 20.6 & 5.7 & 1.7 & $14.8-28.1$ \\
\hline Cereals and legumes $f$ & 37.5 & 5.0 & 1.2 & $27.8-48.2$ & 84.1 & 5.7 & 1.5 & $77.1-89.2$ \\
\hline Fruits and vegetables & 59.0 & 4.7 & 1.1 & $48.3-69.0$ & 92.4 & 5.4 & 1.2 & $86.7-95.7$ \\
\hline Red meat & 5.6 & 5.0 & 0.8 & $2.3-13.1$ & 16.5 & 5.9 & 1.7 & $11.2-23.6$ \\
\hline White meats & 21.5 & 5.4 & 0.6 & $14.0-31.6$ & 51.7 & 6.1 & 1.3 & $43.5-59.8$ \\
\hline Sausages & 2.2 & 5.0 & 1.0 & $0.5-8.8$ & 8.2 & 7.3 & 1.4 & $4.7-14.0$ \\
\hline Egg & 3.4 & 5.0 & 1.0 & $1.0-10.2$ & 24.8 & 7.0 & 1.8 & $18.4-32.5$ \\
\hline Dairy products§ & 21.5 & 4.7 & 1.1 & $14.0-31.6$ & 55.8 & 6.4 & 1.9 & $47.5-63.8$ \\
\hline Miscellaneous * & 21.5 & 5.3 & 0.9 & $14.0-31.6$ & 51.7 & 6.7 & 1.5 & $43.5-59.8$ \\
\hline Bottle fed & 56.8 & - & - & $46.1-66.9$ & 77.2 & - & - & $69.6-83.4$ \\
\hline Add sugar to food & 3.4 & - & - & $1.0-10.2$ & 8.9 & - & - & $5.2-14.9$ \\
\hline Add salt to food & 5.6 & - & - & $2.3-13.1$ & 34.4 & - & - & $27.1-42.6$ \\
\hline Foods high in iron a & 75 & - & - & $64.7-83.0$ & 63.4 & - & - & $55.2-70.0$ \\
\hline Foods high in sugar b & 38.6 & - & - & $28.8-49.3$ & 81.3 & - & - & $74.1-86.9$ \\
\hline \multicolumn{9}{|c|}{ Solid, semi-solid and soft foods } \\
\hline$<6$ months of life & 72.7 & - & - & $62.3-81.1$ & 98.6 & - & - & $94.5-99.6$ \\
\hline
\end{tabular}

$¥$ Milk other than breast; Infant formula, whole milk powder and others;

₹ Non-nutritive liquids; Sweetened water, tea, coffee with water, soda, bean broth, chicken broth, and fruit juice;

+ Nutritive liquids; Atole with water, atole with milk, another cereal with water or milk;

$f$ Cereals and legumes; Pasta soup, rice, tortilla, boxed industrialized baby cereals, bakery bread, industrialized bread, oatmeal, beans, lentils and lima beans;

$\S$ Dairy products; Cheese, Yakult or similar, yogurt and Danonino type;

$€$ Nutrisano; Porridge and supplements from the PROSPERA program;

* Miscellaneous; Fried foods, sweets, cookies or cupcakes;

a Foods high in iron; Red and white meats, cold cuts, Liconsa milk, Nutrisano porridges or PROSPERA supplements;

b High sugar foods; consumption of foods that threaten to exceed $5 \%$ of their total recommended caloric content for the age (sweetened water, soda, industrialized baby cereals, Yakult, Danonino type, candy, cookies or cupcakes). 
total of minors, $58 \%$ were boys and $42 \%$ were girls, the mean age combining both sexes corresponded to $7.3 \pm 2.07$ months. $92.7 \%$ of children lived in households made up of the "father-mother" binomial, the rest lived in households made up of "mother and step-fathers", "mother and grandparents" and "only the mother as head of the household".

\section{Nutritional status}

Related to the nutritional status of the minors, a mean of weight and length was found considering both sexes of $7.7 \pm 1.0 \mathrm{~kg}$ and $67.2 \pm 5.4 \mathrm{~cm}$. Regarding the indicators of weight growth for length (W/L), an indicator taken as a diagnostic criterion, $18.4 \%$ had some degree of malnutrition, $67.8 \%$ a normal nutritional state, $7.7 \%$ were in PROW, $5.6 \%$ were overweight and $0.4 \%$ had a diagnosis of obesity (Table 2 ).

\section{Breastfeeding Practices (BFP)}

Within this framework, $97.4 \%$ of the minors received a breast at some time in the period from birth to the time of the intervention, of these, $80.8 \%$ had an EIBF, concerning EBF only $6.9 \%$ of the children. minors had this practice in the first 6 months of life according to the WHO criteria and $9.7 \%$ of the minors were fed with BFP in the first 6 months of life (Table 3).

We observed that $71.7 \%$ of the minors consumed infant formula, of which $69.5 \%$ reported having problems with breastfeeding such as "I ran out of milk", "did not accept the breast" "deformity in the nipple" "not filling the less". This translates to breastfeeding beliefs.

\section{Feeding practices}

We characterize feeding practices in two groups, younger than six months and older than six months, with we were able to observe differences in the introduction and frequent consumption of different foods. $72 \%$ of those under six months of age received some solid, semi-solid or soft food, while those over six months were $98.6 \%$ before six months of life, this was interpreted as the beginning of complementary feeding of early way.

\section{Under six months}

We were able to observe that the introduction of food in minors began early, with solid and semi-solid foods, we found that the average age of consumption of fruits and vegetables was $4.7 \pm 1.1$ months, cereals and legumes $5 \pm 1.2$, red meat $5 \pm 0.8$. In the case of liquid foods, we observed that plain water was introduced at a mean age of $4 \pm 1.4$, non-breast milk was introduced at $2.7 \pm 1.6$.

Allusive to foods with high sugar content, $38.6 \%$ of those under six months of age consumed foods with these characteristics in which they were found; sweetened water, soda, industrialized cereals, Yakult, Danoninos (Mexican dairy drinks), candy, cookies, or cupcakes, which represents a high consumption in children.

\section{Older than six months}

In the case of those older than six months, the panorama of early initiation of complementary feeding is not very different. We observed that fruits and vegetables began consumption at a mean age of $5.4 \pm 1.2$ frequently, cereals and legumes $5.7 \pm 1.5$ months, and red meat at $5.9 \pm 1.7$ months. In the case of liquid foods, plain water was the main liquid for consumption, however, this was introduced at the age of $4.6 \pm 1.5$ months, milk other than the breast was $3.7 \pm 2.6$ months.

Regarding foods with high sugar content, $81.3 \%$ of the elderly consumed foods with these characteristics in which they were found; sweetened water, soda, industrialized cereals, Yakult, Danoninos type, candy, cookies, or cupcakes, which represents a high consumption in children older than six months. (Table 1).

Model 1 of logistic regression showed that the evaluated children older than six months of age presented significant associations with the variable of interest ( $p=0.04$ ), which represented a 0.5 times greater risk of suffering from PROW, OW, and OB compared with children younger age. In this same model, the consumption of fluids other than the breast within the first three days after birth was significant ( $p=0.02$ ), therefore, they presented about 3.0 times more risk of suffering from the exposed conditions compared to those who did not consume another liquid other than breast in this period. Similarly, the consumption of foods with a high sugar content was found to be highly significant ( $p=0.01$ ) with the variable of interest studied, in this sense, the minors who frequently consumed these foods had 2.5 times the risk of suffering from some condition of PROW, OW and OB (Table 4).

The logistic regression model 2 for the PROW, $\mathrm{OW}$ and $\mathrm{OB}$, found a significant association ( $p=0.02)$ with the consumption of breast milk substitutes, therefore, the consumption of "non-breast milk" frequently represented a 3.2 times higher risk of suffering from PROW, OW, and OB in minors. Finally, although a level of significance was not 
found that could fully associate the consumption of nutritious liquids with the variable of interest, there was a trend in the relationship between both variables $(p=0.08)$ as well as egg consumption $(p=0.056)$ (Table 5).

\section{Discussion}

This research is one of the few in Mexico that prospectively analyzes the different rearing practices that affect PROW and OW + OB within the first year of life. Where it was possible to observe the influence of breast milk substitutes and the introduction of fluids in the first six months of life as risk factors for the development of overweight and early obesity. Different from the information from the ENSANUT
MC 20188 we obtained a lower prevalence of PROW and OW + OB, however, it should be clarified that the data shown by the ENSANUT include the entire population under 5 years of age, which makes a direct comparison impossible between both investigations. However, studies like ours contribute to a clearer vision of the real panorama at specific ages.

Within the observed associations, we found that those children older than 6 months were exposed in a higher proportion to suffer from some condition characterized by excess weight. Specifically, in this period, the literature does not recognize any direct relationship between age and the development of PROW and $\mathrm{OW}+\mathrm{OB}$, but it is known that as age advances, adverse perinatal factors, poor breast-

Table 2

\begin{tabular}{|c|c|c|c|c|}
\hline \multirow[t]{2}{*}{ Category } & \multirow{2}{*}{$\frac{(\mathrm{N}=396)}{\%}$} & \multirow[b]{2}{*}{ Mean } & \multirow[b]{2}{*}{ $\pm S D$} & \multirow[b]{2}{*}{$\mathrm{Cl} 95 \%$} \\
\hline & & & & \\
\hline Age & 100.0 & 7.3 & 2.07 & $7.08-7.62$ \\
\hline Weigth (kg) & 100.0 & 7.7 & 1.07 & $7.60-7.87$ \\
\hline \multirow[t]{2}{*}{ Length (cm) } & 100.0 & 67.2 & 5.41 & $66.57-67.97$ \\
\hline & \multicolumn{3}{|c|}{ Growth indicators } & \\
\hline \multicolumn{5}{|l|}{ Weigth/Age } \\
\hline Low moderate weight & 5.1 & - & - & $2.93-8.88$ \\
\hline Slight underweight & 22.3 & & & $17.39-28.15$ \\
\hline Normal & 63.9 & - & - & $57.53-69.89$ \\
\hline PROW§ & 6.9 & - & - & $4.23-10.95$ \\
\hline Overwegth & 1.7 & - & - & $0.06-4.51$ \\
\hline \multicolumn{5}{|l|}{ Length/Age } \\
\hline Severe short stature & 2.6 & - & - & $1.15-5.64$ \\
\hline Moderate short stature & 6.4 & - & - & $3.90-10.43$ \\
\hline Slight short stature & 24.9 & - & - & $19.72-30.89$ \\
\hline Normal & 66.1 & - & - & $59.73-71.92$ \\
\hline \multicolumn{5}{|l|}{ Weigth/Length ${ }^{\prime}$} \\
\hline Severe Malnutrition & 0.8 & - & - & $0.02-3.39$ \\
\hline Moderate Malnutrition & 3.0 & & & $1.43-6.19$ \\
\hline Mild Malnutrition & 14.6 & - & - & $10.58-19.77$ \\
\hline Normal & 67.8 & & & $61.49-73.53$ \\
\hline PROW§ & 7.7 & - & - & $4.90-11.96$ \\
\hline Overweigh & 5.6 & - & - & $3.25-9.40$ \\
\hline Obesity & 0.4 & - & - & $0.00-3.02$ \\
\hline
\end{tabular}

$\S$ Possible risk of being overweight; It is a trend towards the 2 z-score line which is a definite risk;

+ Indicator taken to diagnose the nutritional status of the minors evaluated. 
Table 3

\begin{tabular}{|c|c|c|}
\hline \multirow[t]{2}{*}{ Category } & $(\mathrm{N}=396)$ & \multirow[t]{2}{*}{$\mathrm{Cl} 195 \%$} \\
\hline & $\%$ & \\
\hline \multicolumn{3}{|l|}{ Breastfeeding Practices } \\
\hline Chest "Ever" & 97.4 & $94.35-98.84$ \\
\hline EIBF $\ddagger$ & 80.8 & $72.06-83.10$ \\
\hline $\mathrm{BFE}^{\dagger}$ & 6.9 & $4.23-10.95$ \\
\hline $\mathrm{PBF} *$ & 9.7 & $4.17-11.13$ \\
\hline \multicolumn{3}{|l|}{ Infant formula } \\
\hline Consumption "Ever" & 71.7 & $65.50-77.12$ \\
\hline \multicolumn{3}{|c|}{ Principal reasons for formula consumtion ${ }^{* *}$} \\
\hline Lactation problems $€$ & 69.5 & $61.98-76.03$ \\
\hline Time & 14.9 & $10.28-21.29$ \\
\hline Others§ & 15.6 & $10.78-21.95$ \\
\hline
\end{tabular}

₹ Early Onset of Breastfeeding; (Children breastfed within 1 hour after birth);

+ Exclusive Breastfeeding; (Minors between 0 and 6 months who received only breast milk);

$¥$ Predominant Breastfeeding (Minors between 0 and 6 months who are non-nutritive fluids and breast milk);

$€$ Lactation problems; "I got sick and couldn't breastfeed" "I ran out of milk", "The baby didn't want the milk"; "Deformity in the nipple"; "Do not fill the child" and "Pain when breastfeeding";

§ Others: "I decided to feed him only by formula", "I decided to breastfeed him and also give him formula", "My son had health problems", "The health personnel recommended it to me", "Friends / family recommended it to me", "I use the that they give me in the program "," Age of the minor "and" For trembling in the hospital ";

** Proportion equivalent to consumption of formula "ever".

Table 4

Model 1 of logistic regression for overweight and obesity and its association with breastfeeding practices.

\begin{tabular}{|c|c|c|c|c|}
\hline \multirow[t]{2}{*}{ PROW/SP/OB } & $(\mathrm{N}=396)$ & \multirow[t]{2}{*}{ Odds Ratio } & \multirow[t]{2}{*}{ Cl95\% } & \multirow[t]{2}{*}{$p<0.05$} \\
\hline & $\%$ & & & \\
\hline \multicolumn{5}{|l|}{ Age (months) } \\
\hline$<6$ & $37.7 \%$ & - & - & - \\
\hline$>6$ & $62.2 \%$ & - & $0.28-1.41$ & 0.043 \\
\hline \multicolumn{5}{|l|}{ Sex } \\
\hline Kids & $58.0 \%$ & - & - & - \\
\hline Girls & $42.0 \%$ & - & $0.27-1.66$ & 0.395 \\
\hline \multicolumn{5}{|l|}{ Gave breast } \\
\hline No & - & - & - & - \\
\hline Yes & $97.4 \%$ & 2.248659 & $0.94-2.99$ & 0.994 \\
\hline \multicolumn{5}{|l|}{ EIBF } \\
\hline No & - & - & - & - \\
\hline Yes & $78.0 \%$ & .4792922 & $0.18-1.24$ & 0.132 \\
\hline \multicolumn{5}{|l|}{ EBFt } \\
\hline No & - & - & - & - \\
\hline Yes & $6.9 \%$ & 5.262606 & $3.30-22.23$ & 0.994 \\
\hline \multicolumn{5}{|l|}{ PBF $¥$} \\
\hline No & - & - & - & - \\
\hline Yes & $6.9 \%$ & 2.055938 & $0.35 \quad 11.99$ & 0.423 \\
\hline \multicolumn{5}{|c|}{ Drinks after birth } \\
\hline No & - & - & - & - \\
\hline Yes & $41.6 \%$ & 2.902787 & $2.12-4.27$ & 0.027 \\
\hline
\end{tabular}

₹ Early Onset of Breastfeeding; (Children breastfed within 1 hour after birth);

+ Exclusive Breastfeeding; (Minors between 0 and 6 months who received only breast milk);

$¥$ Predominant Breastfeeding (Minors between 0 and 6 months who are non-nutritive fluids and breast milk). 


\begin{tabular}{|c|c|c|c|c|}
\hline \multirow[t]{2}{*}{ PROW/SP/OB } & $(\mathrm{N}=396)$ & \multirow[t]{2}{*}{ Odds Ratio } & \multirow[t]{2}{*}{$\mathrm{Cl} 95 \%$} & \multirow[t]{2}{*}{$p<0.05$} \\
\hline & $\%$ & & & \\
\hline \multicolumn{5}{|c|}{ Still breastfeeding } \\
\hline No & - & - & - & - \\
\hline Yes & $82.8 \%$ & .7558515 & $0.23-2.42$ & 0.638 \\
\hline \multicolumn{5}{|l|}{ Add sugar } \\
\hline Yes & - & - & - & - \\
\hline No & $93.1 \%$ & 3.324625 & $0.38-28.56$ & 0.274 \\
\hline \multicolumn{5}{|c|}{ Foods high in iron } \\
\hline No & - & - & - & - \\
\hline Yes & $48.9 \%$ & 2.229576 & $0.75-6.56$ & 0.146 \\
\hline \multicolumn{5}{|c|}{ Food high in sugar } \\
\hline No & - & - & - & - \\
\hline Yes & $65.2 \%$ & 2.508982 & $0.78-3.56$ & 0.015 \\
\hline
\end{tabular}

\# Early Onset of Breastfeeding; (Children breastfed within 1 hour after birth);

+ Exclusive Breastfeeding; (Minors between 0 and 6 months who received only breast milk);

$¥$ Predominant Breastfeeding (Minors between 0 and 6 months who are non-nutritive fluids and breast milk).

Table 5

\begin{tabular}{|c|c|c|c|c|}
\hline \multirow[t]{2}{*}{ PROW/SP /OB } & $(\mathrm{N}=396)$ & \multirow[t]{2}{*}{ Odds Ratio } & \multirow[t]{2}{*}{$\mathrm{Cl} 95 \%$} & \multirow[t]{2}{*}{$p<0.05$} \\
\hline & $\%$ & & & \\
\hline \multicolumn{5}{|l|}{ Formula } \\
\hline No & - & - & - & - \\
\hline Yes & $71.7 \%$ & 1.567375 & $0.59-4.09$ & 0.359 \\
\hline \multicolumn{5}{|c|}{ Hydration serum } \\
\hline No & - & - & - & - \\
\hline Yes & $19.7 \%$ & 2.312167 & $0.58-9.07$ & 0.230 \\
\hline \multicolumn{5}{|c|}{ Milk other than breast } \\
\hline No & - & - & - & - \\
\hline Yes & $42.5 \%$ & 3.259656 & $2.15-4.67$ & 0.025 \\
\hline \multicolumn{5}{|c|}{ Non-nutritive liquids } \\
\hline No & - & - & - & - \\
\hline Yes & $69.1 \%$ & .4752044 & $0.14-1.52$ & 0.211 \\
\hline \multicolumn{5}{|l|}{ Nutritive liquids } \\
\hline No & - & - & - & - \\
\hline Yes & $15.5 \%$ & 6.99792 & $0.78-62.47$ & 0.082 \\
\hline \multicolumn{5}{|c|}{ Cereals and legumes } \\
\hline No & - & - & - & - \\
\hline Yes & $66.5 \%$ & 1.396874 & $0.43-4.51$ & 0.576 \\
\hline \multicolumn{5}{|c|}{ Fruits and vegetables } \\
\hline No & - & - & - & - \\
\hline Yes & $79.8 \%$ & .5786879 & $0.15-2.10$ & 0.407 \\
\hline \multicolumn{5}{|l|}{ Red meat } \\
\hline No & - & - & - & - \\
\hline Yes & $12.5 \%$ & 2.441966 & $0.53-11.11$ & 0.248 \\
\hline \multicolumn{5}{|l|}{ White meats } \\
\hline No & - & - & - & - \\
\hline Yes & $40.3 \%$ & .5062275 & $0.17-1.47$ & 0.213 \\
\hline
\end{tabular}




\begin{tabular}{|c|c|c|c|c|}
\hline PROW/SP /OB & $\frac{(\mathrm{N}=396)}{\%}$ & Odds Ratio & $\mathrm{Cl} 95 \%$ & $p<0.05$ \\
\hline \multicolumn{5}{|c|}{ Meat and sausages } \\
\hline No & - & - & - & - \\
\hline Yes & $6.0 \%$ & 2.580639 & $0.26-25.08$ & 0.414 \\
\hline \multicolumn{5}{|l|}{ Egg } \\
\hline No & - & - & - & - \\
\hline Yes & $16.7 \%$ & .2899289 & $0.18-0.52$ & 0.056 \\
\hline \multicolumn{5}{|l|}{ Egg white } \\
\hline No & - & - & - & - \\
\hline Yes & $4.7 \%$ & .6417283 & $0.06-6.21$ & 0.702 \\
\hline \multicolumn{5}{|l|}{ Dairy products } \\
\hline No & - & - & - & - \\
\hline Yes & $42.9 \%$ & 1.929311 & $0.68-5.46$ & 0.216 \\
\hline \multicolumn{5}{|l|}{ Nutrisano } \\
\hline No & - & - & - & - \\
\hline Yes & $5.6 \%$ & .3110833 & $0.06-1.48$ & 0.143 \\
\hline \multicolumn{5}{|l|}{ Miscellaneous } \\
\hline No & - & - & - & - \\
\hline Yes & $40.3 \%$ & 1.282827 & $0.46-3.52$ & 0.629 \\
\hline
\end{tabular}

feeding practices, and inadequate planning of complementary feeding, reflects the weight gain. ${ }^{17}$ It should be noted that, at the age of 6 months, about $88.8 \%$ of the minors already had established dietary patterns and. In this sense, meta-analyzes on the initiation of complementary feeding have found that the introduction of foods at an early age increases the risk of overweight and obesity in later stages. 18,19

On the other hand, we found that only $6.9 \%$ of the minors complied with the EBF recommendation; These data are below the national figures that have been increasing over the years, ENSANUT 2012 reported $14.4 \%,{ }^{9}$ while ENSANUT 2018 reported $28.6 \% 8$ of children under 6 months who received EBF.

In the present study, no significant association was found between the abandonment of EBF and the development of overweight and obesity, however, various investigations have solidly documented that the absence of EBF is related to the development of overweight and obesity and NCD in early childhood, adolescence, and adulthood. In Mexico, a casecontrol study with 152 infants per group identified the relationship between the absence of EBF and the development of PROW and OW + OB. 20,21 In other countries, research on the effect of EBF on nutritional status in infants also recognizes that the absence of EBF in the first months of life can act as a risk factor in future stages.22,23 Other systematic reviews of cohort studies, clinical trials, descriptive studies, and correlational studies also point to the causality of low SCI over PROW and OW + OB.24,25

In a study carried out in China, it was found that those children and adolescents who had been fed BF for more than 6 months had a protective effect in the presence of Metabolic Syndrome; this result could be observed in children between 10 and 17 years old. 26

On the other hand, independent of age and in contrast to EBF, we found that non-breast milk consumption was associated with PROW and OW + $\mathrm{OB}$ in the younger participants. Within this variable, the highest proportion was occupied by the use of infant formula as a total replacement for breast milk. Although there have been multiple improvement efforts in breast milk substitutes in recent years, the high sugar content combined with the over-feeding of proteins continues to position these products as potential risk factors. 27,28 The aforementioned casecontrol study in Mexican infants also showed relationships between the consumption of infant formula and the development of PRPS and OW + OB. 20 Retrospective studies in children over one year of age also associated the consumption of milk formula with overweight and obesity. 28

In the same way, regardless of age, we discovered that the consumption of products high in sugar 
affected the PROW and OW $+\mathrm{OB}$ in the minor participants. Longitudinal research in children from other countries shows that the introduction of foods with high sugar content before 6 months represents a $92 \%$ risk for overweight and obesity in the next age. ${ }^{29}$ Meanwhile, studies in Latino children have shown a risk of approximately $60 \%$ for overweight and obesity after consuming foods with high sugar content. 29

Regarding the products selected as a risk factor in our study, they were those that presented a threat of exceeding $5 \%$ of the total recommended caloric value in children under 1 year of age according to the WHO. The foregoing in Mexico has been the subject of debate given that the guidelines implemented by the Federal Commission for the Protection against Sanitary Risks (COFEPRIS) are very lax compared to other countries, consequently, the "Nutritional Distinction" that supposes an adequate food for age is voluntary.

Some of the limitations of the work are, the size of the sample depending on the women who belong to the Mexican cohort, therefore, it is not representative at the national level. The observed low prevalence of overweight and obesity depended on the stage of physiological adaptation in which the minors are found, which the first year of life is, coupled with the fact that it is a semi-rural population and does not reach the rural population, it also only focuses a population without social security.

Our results show the importance of addressing inappropriate feeding practices and poor breastfeeding practices in the first year of life, as overweight and obesity prevention measures within programs and policies aimed at health in childhood. In addition to contributing scientific evidence on the importance of breastfeeding, the early consumption of foods high in sugar and fat and of course emphasizing child malnutrition in Mexico.

\section{Author's contribution}

Arredondo A: the conception and design of the work, interpretation of the data, and writing of the manuscript. Lugo OBR and Torres de la Rosa CP: the conception and design of the work, data collection, analysis, interpretation of the data, and writing of the manuscript. Orozco E: a critical review with important contributions and work design. All authors approved the final version of the article.

\section{References}

1. Barker DJP. The origins of the developmental origins theory. J InternMed. 2007; 261 (5): 412-7.

2. Pantoja Ludueña M. Los primeros 1000 días de la vida. Rev Soc Boliv Pediatr. 2015; 54 (2): 60-1.

3. Victora C. Los mil días de oportunidad para intervenciones nutricionales: de la concepción a los dos años de vida. Arch Argent Pediatr. 2012; 110 (4): 311-7.

4. da Cunha AJ, Leite ÁJ, de Almeida IS. The pediatrician's role in the first thousand days of the child: the pursuit of healthy nutrition and development. J Pediatr (Rio J). 2015; 91 (6): S44-51.

5. Saavedra JM, Dattilo AM. Nutrition in the First 1000 Days of Life: Society's Greatest Opportunity a. In: Early Nutrition and Long-Term Health. 2015. p. xxxv-xliv.

6. OMS (Organización Mundial de la Salud). Informe de la Comisión para acabar con la obesidad infantil. Biblioteca de la OMS; 2016.

7. OMS (Organización Mundial de la Salud). Obesidad y sobrepeso; 2018.

8. Shamah-Levy T, Vielma-Orozco E, Heredia-Hernández O, Romero-Martínez M, Mojica-Cuevas J, Cuevas-Nasu L, et al. Encuesta Nacional de Salud y Nutrición 2018-19: Resultados Nacionales. Cuernavaca, México: Instituto Nacional de Salud Pública; 2020.

9. Gutiérrez JP, Rivera-Dommarco J, Shamah-Levy T,

Villalpando-Hernández S, Franco A, Cuevas-Nasu L, Romero-Martínez M, Hernández-Ávila M. Encuesta Nacional de Salud y Nutrición 2012. Resultados Nacionales. Cuernavaca, México: Instituto Nacional de Salud Pública (MX), 2012

10. Franco LV. Obesidad. Espejismo de salud y belleza en niños lactantes. [Editorial]. Rev Mex Pediatr. 2003; 70 (6): 271-2.

11. Reilly J, Methven E, McDowell ZC, Hacking B, Alexander D, Stewart L, Kelnar C. Health consequences of obesity. Arch Dis Child. 2003; 88 (9): 748-52.

12. McCormick DP, Sarpong K, Jordan L, Ray LA, Jain S. Infant Obesity: Are We Ready to Make this Diagnosis? J Pediatr. 2010; 157 (1): 15-9.

13. Finer N. Medical consequences of obesity. Med (United Kingdom). 2015; 43 (2): 88-93.

14. Arredondo A, Torres C, Orozco E, Pacheco S, Huang F, Zambrano E, Bolaños-Jiménez F. Socio-economic indicators, dietary patterns, and physical activity as determinants of maternal obesity in middle-income countries: Evidences from a cohort study in Mexico. Int J Health Plann Manage. 2018; (August): 1-13.

15. Arredondo A, Torres C, Orozco E, Pacheco S, Huang F, Zambrano E. Indicadores socioeconómicos de la obesidad materna en México y Francia. Análisis comparado de dos cohortes. Rev Salud Pública. 2018; 20 (2): 245-53. 
16. OMS (Organización Mundial de la Salud). Patrones de crecimiento del niño de la OMS; 2008.

17. Skelton JA, Irby MB, Grzywacz JG, Miller G. Etiologies of obesity in children: Nature and nurture. Pediatr Clin North Am. 2011; 58 (6): 1333-54.

18. Wang J, Wu Y, Xiong G, Chao T, Jin Q, Liu R, Hao L; Wei $\mathrm{S}$; Yang N; Yang X. Introduction of complementary feeding before 4 months of age increases the risk of childhood overweight or obesity: A meta-analysis of prospective cohort studies. Nutr Res. 2016; 36 (8): 759-70.

19. Cu L, Villarreal E, Rangel B, Galicia L, Vargas E, Lidia \& M. Factores de riesgo para sobrepeso y obesidad en lactantes Risk factors for overweight and obesity in infants. Rev Chil Nutr. 2015; 42 (13): 139-44.

20. Basain Valdés J, Pacheco Diaz L. Duración de lactancia materna exclusiva, estado nutricional y dislipidemia en pacientes pediátricos. Rev Cubana Pediatr. 2015; 87 (2): 156-66.

21. Park SJ, Lee HJ. Exclusive breastfeeding and partial breastfeeding reduce the risk of overweight in childhood: A nationwide longitudinal study in Korea. Obes Res Clin Pract. 2018; 12 (2): 222-8.

22. Aguilar MJ, Sanchez AM, Madrid N, Mur N, Expósito M, Hermoso E. Lactancia materna como prevención del sobrepeso y la obesidad en el niño y el adolescente; revisión sistemática. Nutr Hosp. 2015; 31 (2): 606-20.
23. Jing Y, Lin L, Zhu Y, Huang G, Peizhong PW. The association between breastfeeding and childhood obesity: a metaanalysis. BMC Public Heal. 2014; 14: 1267.

24. Pearce J, Langley-Evans SC. The types of food introduced during complementary feeding and risk of childhood obesity: a systematic review. Int J Obes. 2013; 37 (10): 1295-306.

25. Vásquez-Garibay EM. Primer año de vida. Leche humana y sucedáneos de la leche humana. Gac Med Mex. 2016; 152: 13-21.

26. Wang J, Zhu Y, Cai L, Jing J, Chen Y, Mai J, Ma L, Ma Y, Ma J. Metabolic syndrome and its associated early-life factors in children and adolescents: a cross-sectional study in Guangzhou, China. Public Health Nutr. 2016; 19 (7): 1147-54.

27. Bogen DL, Hanusa BH, Whitaker RC. The effect of breastfeeding with and without formula use on the risk of obesity at 4 years of age. Obes Res. 2004; 12 (9): 1527-35.

28. Pan L, Li R, Park S, Galuska DA, Sherry B, Freedman DS. A longitudinal analysis of sugar-sweetened beverage intake in infancy and obesity at 6 years. World Rev Nutr Diet. 2016; 114 (September): 34-5.

29. Davis JN, Whaley SE, Goran MI. Effects of breastfeeding and low sugar-sweetened beverage intake on obesity prevalence in Hispanic toddlers. Am J ClinNutr. 2012; 95 (1): 38 .

Recived on February 8, 2021

Final versión presented on August 9, 2021

Approved on September 20, 2021 